Interindividual Age Differences in Personality Structure

Emorie D Beck

David M Condon

Joshua J Jackson

Correspondence concerning this article should be addressed to Emorie D Beck, 1 Brookings Dr., St. Louis, MO 63130.Email: edbeck@wustl.edu.

Open materials on GitHub (https://github.com/emoriebeck/age_nets) contain raw data files, results, and code used to conduct the analyses in this manuscript as well as a number of additional analyses. 


\begin{abstract}
Most investigations in the structure of personality traits do not adequately address age; instead they presuppose a constant structure across the lifespan. Further, few studies look at the structure of personality traits a-theoretically, often neglecting to examine the relationship among indicators within a trait (coherence) and across traits (differentiation). Using a network approach, the present study examines (1) age differences in differentiation and coherence, (2) the similarity between the Big Five and network structures, and (3) the consistency of network structure across age groups in a large, cross-sectional sample. Results indicate that coherence shows early gains in adolescence with few changes across the lifespan, while differentiation mostly weakens across adulthood. The result of these age-related changes is that Big Five indicators only parallel the Big Five structure among young but not older adults. The structure of young adults tends to be quite similar while the network structures of older adults appear to greatly differ from one another. These results suggest that older adults have a different structure of personality than younger adults and suggest that future research should not assume consistency in personality structure across the lifespan.
\end{abstract}




\section{Interindividual Age Differences in Personality Network Structure}

Personality assessment has a rich history dating back almost 100 years (Allport, 1937). In the psycholexical tradition (Allport \& Odbert, 1936; Galton, 1884), personality scientists have spent several decades mapping the structure of between-person individual differences. Across many teams of researchers, findings converged on a parsimonious solution with five bipolar dimensions - Extraversion, Agreeableness, Conscientiousness, Neuroticism, and Openness to Experience - the Big Five (Goldberg, 1990). Beyond mere description of self-reported individual differences, the Big Five has been shown to predict a wide range of behaviors and important life outcomes, including: mortality/health (Jackson, Connolly, Garrison, Leveille, \& Connolly, 2015; Weston, Hill, \& Jackson, 2015); educational (Busato, Prins, Elshout, \& Hamaker, 2000; De Raad \& Schouwenburg, 1996) and occupational attainment (Barrick \& Mount, 1991; Barrick, Mount, \& Judge, 2001); financial status (Duckworth, Weir, Tsukayama, \& Kwok, 2012) and spending patterns (Weston, Gladstone, Graham, Mroczek, \& Condon, 2019); and romantic (Donnellan et al., 2005; Robins et al., 2002; Solomon \& Jackson, 2014), family (Belsky et al., 2003), and friend (Harris \& Vazire, 2016; Wilson, Harris, \& Vazire, 2015) relationships. In addition, there now exists a deep literature describing the extent to which the Big Five have been recovered across cultures (Benet-Martínez \& John, 1998; McCrae \& Terracciano, 2005), languages (Denissen, Geenen, van Aken, Gosling, \& Potter, 2008; Saucier \& Ostendorf, 1999), and age categories (Marsh, Nagengast, \& Morin, 2012; McCrae et al., 1999).

However, this latter body of research focused on recovery of the Big Five across cultures, languages and age has depended almost exclusively on the use of factor analytic techniques (Block, 2010; Borsboom, Mellenbergh, \& Van Heerden, 2003; Marsh et al., 2012). The near universal use of this analytic technique has bolstered consensus around the Big Five model 
which has, in turn, benefited personality researchers by providing a common framework to replace unitary constructs and by helping to partially overcome a jingle-jangle cacophony that held back the field. But factor analysis is not the only option among latent variable modeling techniques. While the depth of the literature supporting replicability of the Big Five may not seem to call for further evaluation of its validity, there is also considerable evidence that the assumptions of factor analysis are often violated. This is particularly true when considering Big Five structure across the lifespan. Evidence for the lack of measurement invariance across age (Marsh et al., 2012; Nye , Allemand, Gosling, Potter, \& Roberts, 2016; Olaru, Schroeders, Wilhelm, \& Ostendorf, 2018; Tackett et al., 2009) and distinct trajectories for facets of the same Big Five traits (Jackson et al., 2009; Soto, John, Gosling, \& Potter, 2011; Soto \& John, 2011) suggest that the content of the Big Five dimensions - and the generalizability of the Big Five structure - may vary across the lifespan. The current study sought to evaluate the structure of the Big Five across the lifespan using a novel network approach rather than traditional factor analytic techniques. Before describing this work, we begin by summarizing the benefits of considering alternative approaches relative to relying on factor analysis to uncover the structure of personality.

\section{Beyond Internal Consistency: Coherence and Differentiation}

There is a large body of evidence tracking the consistency and change of the Big Five across the lifespan. However, there are fewer studies looking at whether the Big Five structure replicates across age groups, also known as structural consistency. Typical age-related examinations of the Big Five test whether the structure can be "found" across different age groups (e.g. Marsh et al., 2012; McCrae et al., 1999) based on the fit statistics of confirmatory factor analyses. However, these investigations are typically neither systematic nor without 
preconceived notions about the structure, many employing Procrustes rotations that strongly favor a Big Five structure (McCrae et al., 1996). Other studies have focused on measurement invariance of factors, attempting to see whether the Big Five factors are interpretable as the same construct across age groups (Allemand, Zimprich, \& Hertzog, 2007; Allemand, Zimprich, \& Hendriks, 2008; Jackson et al., 2009; Mõttus, Johnson \& Deary, 2012; Small et al., 2003). Testing the Big Five structure across age groups could be instead contrasted with an open approach asking what factor structure best captures different age groups, without an a priori notion about the structure. In other words, what almost no study asks is what structure fits best, especially for older adults?

Such an alternative approach calls for examination of the properties of coherence and differentiation (see Soto, John, Gosling, \& Potter., 2008 for a discussion of these within adolescents). Within-domain coherence is closely related to internal consistency (like the oftused coefficient alpha) and examines whether the items intended to measure the same trait are highly correlated with one another. In other words, coherence captures the inter-reliability, but not the unidimensionality of a scale (Revelle \& Condon, in press). Differentiation is the complement of coherence, indexing how strongly any two items across traits are related. Typically, coherence is operationalized as the average inter-item correlation for all items within a scale, while differentiation is the average inter-item correlation for all items across two or more scales. Ideally, measurement models with multiple constructs will show both high coherence (high inter-item correlations) and high differentiation (low inter-item correlations for items on different sub-scales), consistent with so-called "simple structure" (Petterson \& Turkheimer, 2010). It has historically been common for measurement developers to focus on internal consistency as a marker of the adequacy of their scales while ignoring differentiation. The 
evidence for this is the over-reporting of coefficient alpha (McNeish, 2018), the under-reporting of factor congruences (Lorenzo-Seva \& Ten Berge, 2006), and the inability to demonstrate simple structure in Big Five scales due to non-trivial cross-loadings (Hopwood \& Donnellan, 2010).

The focus on coherence extends to tests of measurement invariance. Evaluations of measurement invariance test whether factor loadings, intercepts, and residual variances of latent constructs are equivalent, as this is necessary for valid comparison of personality across groups and/or over time (Jackson \& Allemand, 2014). But much like coefficient alpha, measurement invariance seeks to capture the consistency of what is common to a measured (latent) construct, not to assess whether the indicators are unidimensional or that differentiation of items across scales is high. Thus, differentiation among constructs is often largely ignored in favor of evaluations of coherence within constructs. Even with the over emphasis on coherence, measurement invariance across time or age is not always found (Marsh et al., 2012; Nye et al., 2016; Olaru et al., 2018; Tackett et al., 2009)

A number of options have been put forth in response to the tendency of measurement models of the Big Five to not fit well (Hopwood \& Donnellan, 2010). On the one hand, the misfit can be explained away, as one should not expect a good fit given the complexity of personality. Instead, the use of other criteria to validate the factors are necessary (e.g., external validity) in light of poor fit. On the other hand, theorits have suggested (i.e., Hopwood \& Donnellan, 2010) that novel methods should be employed to identify alternatives structure of personality that may extend beyond the Big Five. The current paper takes the latter approach. Personality Networks 
In contrast to standard factor analytic methods, the recent introduction of psychometric network models offers an alternative approach for explaining how and why the Big Five structure emerges (Costantini \& Perugini, 2016; Cramer et al. 2012). To date, these models have been sparingly used in personality despite their promise (Beck \& Jackson, 2019; Costantini \& Perugini, 2016; Cramer et al. 2012; Schmittmann et al., 2013). Network models have the advantage of not presupposing latent constructs and can directly assess coherence and differentiation. At the most general level, network models allow the visualization of correlations and covariances. Of specific interest are partial correlation networks, where the relationships between indicators (nodes) represent conditional dependence between nodes after conditioning on all other indicators in the network (Epskamp \& Fried, 2016). Conditional dependence is a proxy for coherence - indicators within coherent scales should be highly related, even after conditioning on other indicators. In contrast, the absence of an association represents conditional independence between nodes. Conditional independence is a proxy for differentiation - well differentiated scales should be uncorrelated.

Network models have three clear advantages over latent trait models for the investigation of factor structure across age groups. First, network models are agnostic to boundaries between traits, meaning that conditional dependence (coherence) and independence (differentiation) can both be readily observed within and between different personality traits, as defined as items within current Big Five scales. Second, undifferentiated boundaries between traits freely allow and accommodate violations of measurement invariance. By examining patterns of conditional independence and dependence both between and within indicators of putative personality traits, researchers can map changes in manifestations of traits across the lifespan. 
Third, by removing the emphasis on mean levels of traits or indicators, personality networks offer a new conceptualization of the consistency of personality across the lifespan. While factor models assume that indicators within a factor are independent after conditioning on the latent variable and that change or development occur at the level of a latent variable, rather than its indicators, networks allow items both within and across constructs to correlate. To the extent that items within traits correlate differently with one another or with indicators of different traits, different item-level developmental patterns should be expected. Like congruence coefficients in factor analytic models, the consistency of a personality system can be mapped across the lifetime by looking at the profile of relationships among indicators over time (c.f. Beck \& Jackson, 2019) or across different age groups. Somewhat akin to test-retest consistency, this allows researchers to test the consistency of both coherence (within-trait relationships) and differentiation (between-trait relationships) within a unitary framework that accounts for dependence between the two.

\section{Big Five Personality Development}

Across a number of longitudinal and cross-sectional studies there is evidence that the mean-level personality trait scores change with age (Donnellan \& Lucas, 2008; Lucas \& Donnellan, 2009; Roberts \& Mroczek, 2008; Soto et al., 2011; Specht, Egloff, \& Schmukle, 2011). These changes are most pronounced in young adulthood and older age, each a time period where there are rapid physical changes as well as changes in social roles. Despite consistent patterns of normative Big Five change, it is unclear how to interpret such change as most Big Five inventories were developed and validated using samples of young adults, particularly undergraduates (Norman, 1963; Cattell et al., 1970; Digman \& Takemoto-Chock, 1981; Goldberg, 1990) and young Air Force officers (Tupes \& Christal, 1961). It may be that changes 
are artifactual if the Big Five does not accurately capture the structure of personality at later ages - that is, changes may reflect structural change rather than mean-level change (Jackson \& Allemand, 2014). Given that personality change in middle and older adulthood has been linked to important life outcomes, like health (Jackson, Weston \& Schultz, 2017; Turiano et al., 2015), it is vital to understand the processes underlying the structure of individual differences at different points in development.

Changes in one's everyday environment, social structure, and daily responsibilities ebb and flow across the life course as one traverses the age graded experiences of gains and losses (Baltes, 1997; Freund, Li, \& Baltes, 1999). As such, behavioral patterns and personality manifestations may become more idiosyncratic throughout the lifespan, which may both quantitatively and qualitatively influence personality structure. For example, the transition to retirement impacts the manifestations of Conscientiousness (Mike, Jackson and Oltmanns, 2014). In line with this, longitudinal twin studies suggest that non-shared environmental characteristics increasingly influence personality throughout the lifespan (Tucker Drob \& Briley, 2014), suggesting that idiosyncratic experiences accumulate to influence personality over time. Thus, it is quite possible that the structure of personality in adolescence and young adulthood does not mirror the structure in older adulthood.

Limited work has investigated coherence and differentiation across the lifespan. In adolescence, both within-trait coherence and between-trait differentiation increase between ages 10 and 20, but the patterns differ across traits (Soto et al., 2008). In the only study that examines older adults, Agreeableness, Neuroticism, and Conscientiousness demonstrate very similar patterns of coherence and differentiation - modest increases in both across the full life span (Soto et al., 2011). In contrast, Extraversion gains steeply in cohesion but stays similarly 
differentiated. These studies are limited by a number of factors, however. First, differentiation and coherence are not statistically independent from one another and the aforementioned studies did not account for the overlap between the two. Second, differentiation was assessed at the trait level, not at the item-level. As a result, a true comparison of age differences in "cross loadings" has yet to be tested.

\section{The Present Study}

In the present study, we use a large-scale cross-sectional data to test coherence and differentiation trends between and within domains of the Big Five using the IPIP50. We address three main questions. First, when accounting for dependencies across scales (i.e., using multitrait networks where all of the Big Five indicators are assessed simultaneously), how coherent and differentiated are the Big Five across the lifespan? Based on previous research, we expect both coherence and differentiation to show steep improvements in adolescence, after which coherence should continue to increase throughout the lifespan, while differentiation will slowly weaken.

Second, what is the network structure of the Big Five across the lifespan and how does this compare to its putative Big Five structure? We test whether community analysis, a network method for assessing structure which accounts for cross-trait and within-trait relationships, recovers a Big Five structure across the lifespan. Based on the preliminary work, we expect that the Big Five structure will emerge. However, given that most preliminary work assumes a Big Five structure, we do not hold strong expectations.

Third, how consistent is the network structure of the Big Five across the lifespan, and is this consistency similar for items within and across scales? Test-retest correlations non-linearly decrease as the measurement interval increases (Fraley, 2005). If changes in coherence and 
differentiation are gradual, then the consistency of network edge weight profiles should be quite high when age differences are small and lower when age differences are large. We would expect that profile correlations non-linearly decrease with greater age gaps, but that this will not vary as a function of age. In other words, the profile correlation between 15 and 20 year-olds should be roughly equal to that between 55 and 60 year-olds, but each of these will be different from the profile correlations between 15 and 30 year-olds and 55 and 70 year-olds.

\section{Methods}

\section{Participants}

Participants were 369,151 individuals (64\% female) who completed an online survey at SAPA-Project.org (previously test.personality-project.org) between April 4, 2006 and February 7, 2017 in exchange for customized feedback about their personalities. All data were selfreported and participants were only required to provide age and gender information in order to receive feedback. The mean self-reported age was 26.4 years $(S D=10.9$, median $=22)$ with a range from 14 to 90 years. While a wide range of educational attainment levels were represented (see Table 2), approximately $43 \%$ of participants reported being current university or secondary school students. Of the 347,672 participants who reported their country of origin, $72.5 \%$ were from the United States; 67 countries were represented by at least 200 participants and 226 countries were represented in total (using the country codes maintained by the International Organization for Standardization). Additional demographic information about the sample is provided in the online materials.

\section{Measures}

Participants were administered random subsets of the 100 items corresponding to the Big Five Factor Markers (Goldberg, 1992) from the International Personality Item Pool (Goldberg, 
1999; Goldberg et al., 2006). The item sampling procedures made use of the Synthetic Aperture Personality Assessment (“SAPA”) technique (Revelle et al., 2016), a variant of matrix sampling procedures discussed by Lord (1955). The number of items administered to each participant varied over the course of the sampling period (mean $=32$; median $=47 ; S D=18)$ and was independent of participant characteristics. The number of administrations for each item varied considerably $($ mean $=118,299 ;$ median $=116,424 ; S D=10,560)$ as did the number of pairwise administrations between any two items in the set $($ mean $=49,137$; median $=35,993 ; S D=$ 26,592). The minimum number of pairwise administrations among items $(15,404)$ provided sufficiently high stability in the covariance matrix for the structural analyses described below (Kenny, 2016). Further evidence of stability is provided by the bootstrapped estimates of the standard errors of the correlations (see Supplementary Figure 2 in Chapter 2 of the online materials at emoriebeck.github.io/age_nets); virtually all of the 95\% confidence intervals around the correlations at the item levels were less than .02 .

\section{Analysis Plan}

The analyses reported here focused only on the 50-item version of the items corresponding to the Big Five factor markers (“IPIP50”), though results for the Mini-IPIP (Donnellan, Oswald, Baird, \& Lucas, 2006) and all 100 items corresponding to the Big Five factor markers (Goldberg, 1992) are given in the online materials at emoriebeck.github.io/age_nets. As the results converged across each of the scales, the decision to present on the IPIP50 was based on the ease of visualization and interpretation of results, which becomes much more complex as the length of the scale increases.

For each age, we computed a weighted, signed, and undirected partial correlation network. We did this both using the full IPIP50 (multi-trait networks) as well as for each scale 
within the IPIP50 (single trait networks). In network science, the definition of nodes and edges is critical. In this paper, we take a theory-based approach to their definition, assuming that the Big Five, as operationalized in the IPIP50, encompasses the personality space. As such, each node in the networks represents a dispositional rating of an emotion or behavior. Edges represent direct positive and negative relationships between individuals' ratings. Moreover, because these are partial correlations, edges represent the unique relationships between each item pair. The network edges are regularized using graphical LASSO (glasso; Friedman, Hastie, \& Tibshirani, 2008) regularization. glasso is a faster variant of the "least absolute shrinkage and selection operator" (LASSO; Friedman et al., 2008; Tibshirani 1996). Essentially, glasso is an iterative algorithm that shrinks the size of the network to reduce spurious connections by setting them to zero. The more connections that are removed, the sparser the network. The penalization of glasso varies depending on sample size. Because we used a planned missing data design, we use the maximum number of responses to an IPIP50 item within each age group separately, which is always substantially less than the total number of participants in each group. The sparsity of the network is further controlled by a tuning parameter. We allow that tuning parameter to vary, instead setting the hyperparameter of the extended Bayesian Information Criterion (EBIC; Chen and Chen, 2008). Simulation studies of the specificity and sensitivity of network models using EBIC with different sample sizes provide guidelines for setting the EBIC hyperparameter (Epskamp, 2016). For sample sizes above 1000, we set the EBIC hyperparameter to .5, while for smaller samples, we set the EBIC hyperparameter to .25 . In doing so, we calculate a network that is relatively sparse but that minimizes EBIC to ensure good model fit. To display the resulting networks, we use the Fruchterman-Reingold algorithm (Fruchterman \& Reingold, 1991), which is a force directed algorithm. Because the algorithm relies on random walks among nodes, we 
calculate 1000 iterations for each network and compute the average layout. All networks were estimated using the R package qgraph (Epskamp, Cramer, Waldorp, Schmittmann, \& Borsboom, 2012).

Next, for each network, we assess the community structure of the graph (Reichardt \& Bornholdt, 2006). In personality networks, communities are behaviors that are strongly interconnected with each other but not other nodes. From a nomothetic perspective on personality, we would expect communities to match up with the Big Five factor structure. There are several unique approaches for identifying nodes within a community. One approach is the Louvain method (Blondel, Guillaume, Lambiotte, Lefebvre, 2008). This approach has several advantages, including its fast computation time, even within large networks, and its allowance for hierarchical structure. The procedure is iterative and consists of two phases. First, it examines small, local patterns of modularity (e.g. nodes that seem to perform a specific, unique function). Second, it collapses across nodes of the same "small" community and creates a new network in which the communities are the nodes. The procedure is repeated until the resulting network achieves maximum modularity. We estimate the community structure of each network using the R package igraph (Csardi \& Nepusz, 2006).

Finally, we assess the consistency of associations across the lifespan. Doing so allows us to answer two questions. First, are the age differences in differentiation and coherence evident in relatively gradual broader structural changes throughout the lifespan? Changes in coherence and differentiation should be relatively continuous, and individuals close in age should have more similar personalities than individuals more distant in age. Stated differently, we would expect network structure similarity to be a function of age differences, not age itself (e.g. the age difference between 15 and 20 is the same as between 55 and 60). Second, how well does the Big 
Five work for all age groups? In other words, is there evidence for structural consistency in the Big Five across the lifespan? To answer these questions, we assessed the stability of network associations across ages by calculating the profile correlation for all pairwise combinations of networks - that is, calculating the profile similarity across all ages. Network structure is highly dependent on the profile of edge weights (Fruchterman \& Reingold, 1991), so profile similarity is a reasonable approximation of network similarity in weighted, signed networks.

\section{Results}

\section{Age Differences in Coherence and Differentiation}

We first examine coherence and differentiation in networks containing all items from the IPIP50 using a network approach. Previous tests of coherence and differentiation focused on trait items using measures of internal consistency, like inter-item correlations, that ranged from .15 to .40 (differentiation) and .15 to .55 (coherence; Soto et al., 2008, 2011). In contrast, a network approach indexes coherence using average inter-item regularized partial correlations within traits and differentiation using average cross-trait inter-item regularized partial correlations. This allows us to examine coherence while controlling for differentiation and vice versa. Assuming a scale is performing as expected, coherence should be higher than differentiation - relationships between items in a scale should be more related to one another than items across scales.

Figure 1 presents the estimates of coherence (green line) and differentiation (blue line) for all age groups across the lifespan. Coherence is higher than differentiation across the lifespan, dropping slightly in adolescence from .12 to .10 and remaining relatively stable throughout the lifespan, with a slight increase in young adulthood and then a decrease in older adult, reaching its peak at approximately .14. Differentiation increased during adolescence (ie a decrease in average edge weight), reaching its peak (indicated by the local minima in average edge weights) between 
ages 16 and 18. It is during these ages that indicators of the Big Five traits show the smallest number of "cross-loadings." Across adulthood, differentiation weakened as shown by the increase in average edge weights from approximately .03 at age 18 to approximately .11 at age 60. These results reflect few changes in coherence from adolescent through adulthood, reflecting that within trait correlations are relatively similar across adulthood. In contrast, concurrent drops in differentiation (e.g., increasing edge weights) indicate greater associations across trait boundaries, potentially implying that the Big Five structure does not hold at older ages.

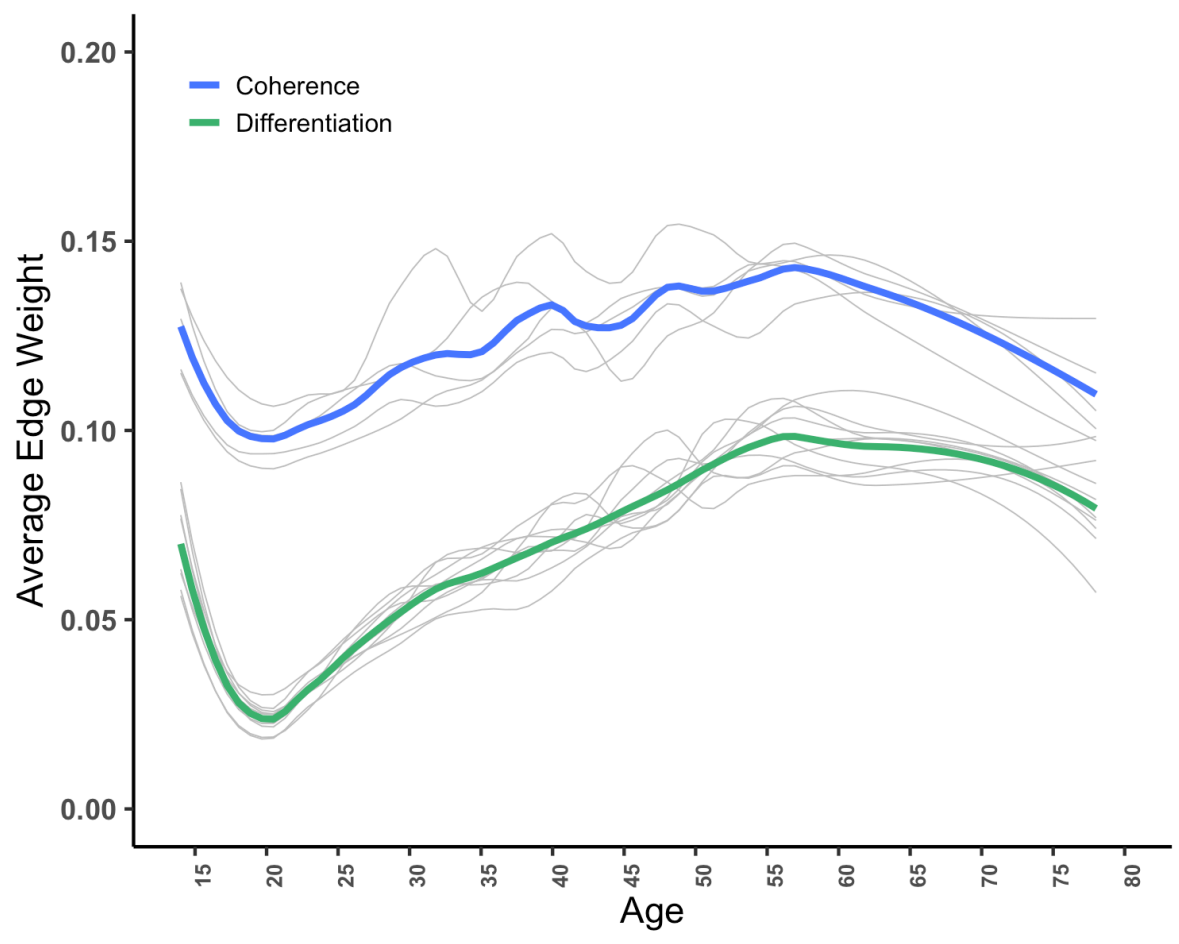

Figure 1. Coherence (green) and differentiation (blue) across the lifespan. Coherence is indicated by higher average inter-item partial correlations within scales, while differentiation is indicated by lower average-inter-item partial correlations across sub-scales of the Big Five. Thus, increases in the blue differentiation line indicate decreases in differentiation and vice versa. Light gray lines show the unique trajectory for each of the Big Five.

\section{Multi-Trait Versus Single-Trait Networks}


The comparable age differences in coherence and differentiation across the lifespan suggest that coherence and differentiation are not independent. To evaluate this, we compared two models that differ only in whether differentiation is simultaneously estimated - that is, a model that contains all traits (a multi-trait model, as presented above, where the Big Five are estimated simultaneously) and their indicators compared with models that contains each trait separately (five separate single trait models). Differences between these models would suggest the extent to which differentiation influences estimates of coherence. To the extent that the traits are differentiated, relationships within traits should not be greatly impacted by partialling out the variance attributable to associations with items from other traits. If the Big Five traits are well differentiated then edge weights in single trait networks should closely resemble those of the multi-trait network. Departures would suggest that relationships between traits impact relationships within a trait, indicating weak differentiation (i.e., cross loadings).

Each panel of Figure 2 charts the impact of partialling out the variance due to differentiation on coherence within a single trait. Multi- and single-trait networks roughly parallel each other until around age 45 (Agreeableness), 50 (Conscientiousness, Neuroticism) or 55 (Extraversion, Openness), at which point the coherence of the single trait networks spikes dramatically. In other words, traits are not clearly differentiated above age 55 indicating greater average associations between items on different traits. Moreover, with edge weights non-trivially different from zero, perfect differentiation does not exist for any age as would be expected if simple structure held. These findings indicate that the Big Five do not adhere to a simple structure, and the misfit worsens among older adults. 


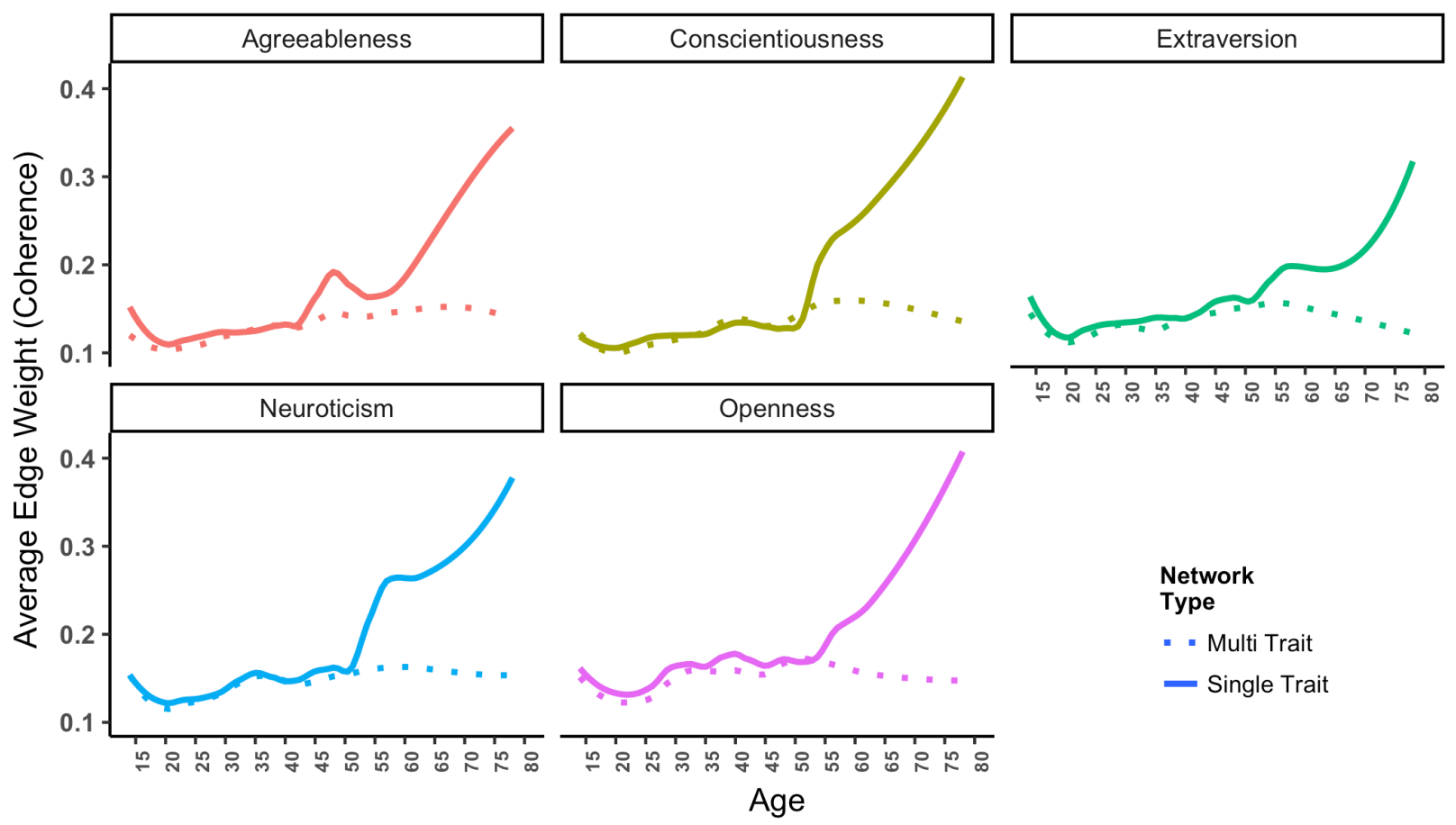

Figure 2. Coherence across the lifespan by trait. Solid lines indicate coherence when each trait was modeled separately, while dotted lines indicate coherence when the full IPIP-50 Big Five scale was modeled simultaneously. Coherence is indicated by higher average inter-item partial correlations within scales; thus increases in coherence across age groups suggests increasing coherence.

\section{Community Structure}

Next, we assessed the community structure of the networks at each age to test whether the Big Five structure was recovered using partial correlations among the full Big Five across different ages. Higher coherence than differentiation suggests that this is likely, but we can formally test this by examining the community structure of the networks at each age. Communities in networks are indicated by strong connections within a community and weak connections across them. 
For parsimony, Figure 3 shows the network graphs for two age groups: young adults in their 20s and older adults in their 60s. Networks for each age group are included in the online materials. In the networks, nodes (items) are color-coded by Big Five domain and the colored border represents the statistically derived Louvain community structure. There are two notable takeaways from these network graphs. First, as the figure demonstrates, the community structure of young adults in their 20s closely matches the Big Five structure, whereas the adults in their 60s do not. In Figure 3, close structural matching with the Big Five is represented by nodes whose fill color matches the color of the border, while lack of matching is represented by mismatch between node fill color and border color.

Second, there are many more edges connecting nodes across traits in the network of adults in the $60 \mathrm{~s}$ - that is, the network density of those in their $60 \mathrm{~s}$ is much higher than that of those in their 20s. This converges with the observation of worsening differentiation across the lifespan on average. The indicators appear to become less distinct among older adults. This implies that for older adults, nearly any item selected at random would appear to be an equally good measure of any of the Big Five. 

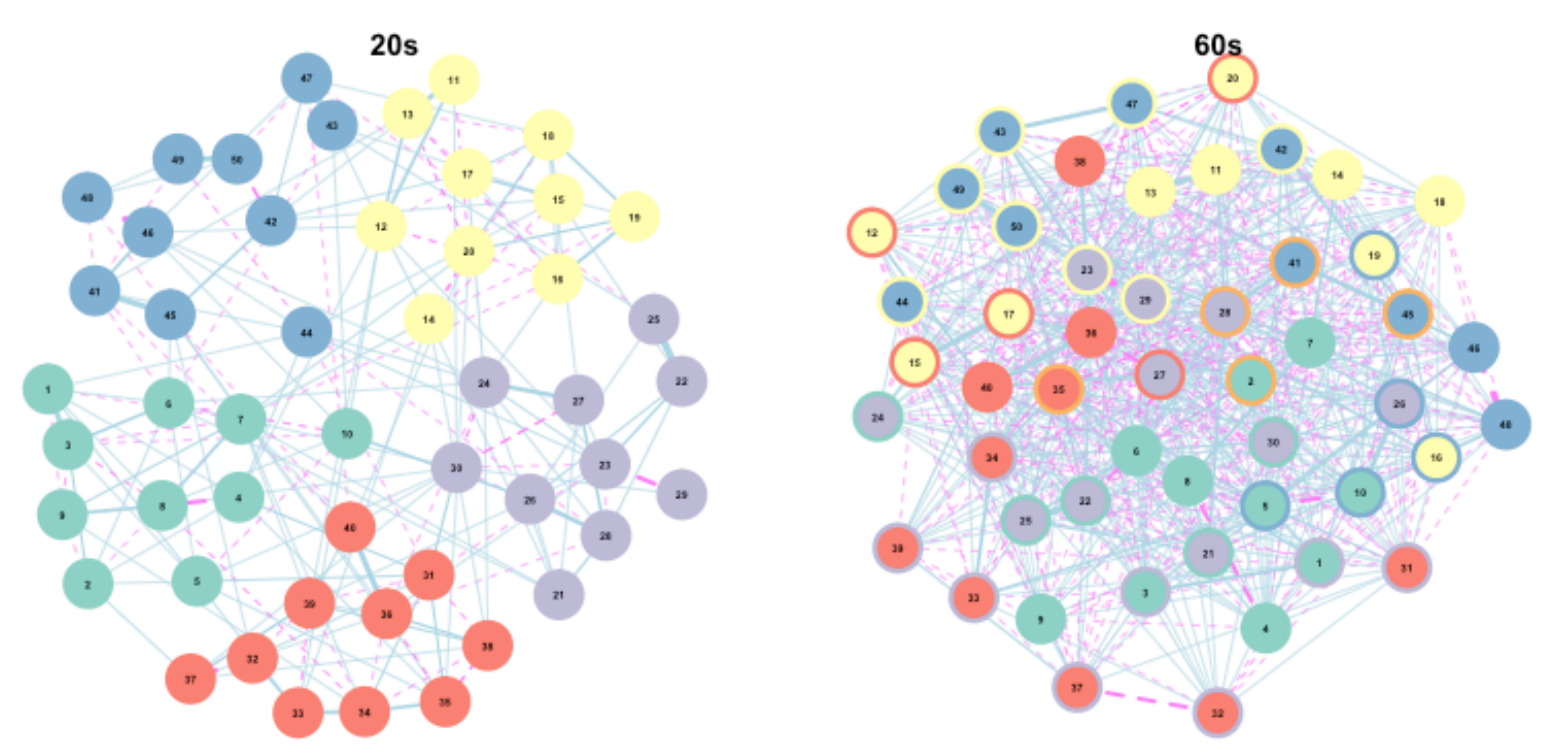

Figure 3. Item networks by age group. Nodes (circles) represent unique IPIP-50 items. Nodes colors are colored according to their putative Big Five scale membership, while node borders are colored according to their empirically derived community membership. Edges (lines between nodes) indicate partial correlations. Solid lines indicate positive relationships, while dashed lines indicate negative relationships.

To further test how closely the structures matched across age groups, we also examined the frequency of two nodes (IPIP 50 items) sharing community membership across all ages. Figure 4 shows the frequency across all ages (Figure 4a), among ages 38 and below (Figure 4b), and for ages 39 above (Figure 4c). ${ }^{1}$ Darker colors signify higher frequencies. Darker colors along the diagonals reflect higher frequencies of shared community membership among items within the same Big Five trait. Perfect simple structure would result in 5 dark triangles along the diagonal and light colors everywhere else. For those under 38, this is the pattern found,

\footnotetext{
${ }^{1}$ Age groups were split into 38 and below and 39 and above because this was a median split of the 50 age groups we examined. Similar plots are found when splitting at different ages.
} 
consistent with a Big Five structure. However, for those older than 38 there does not appear to be a unified structure. The proportion of shared community membership is much less frequent among the older age groups, again demonstrating greater differentiation with age.

All

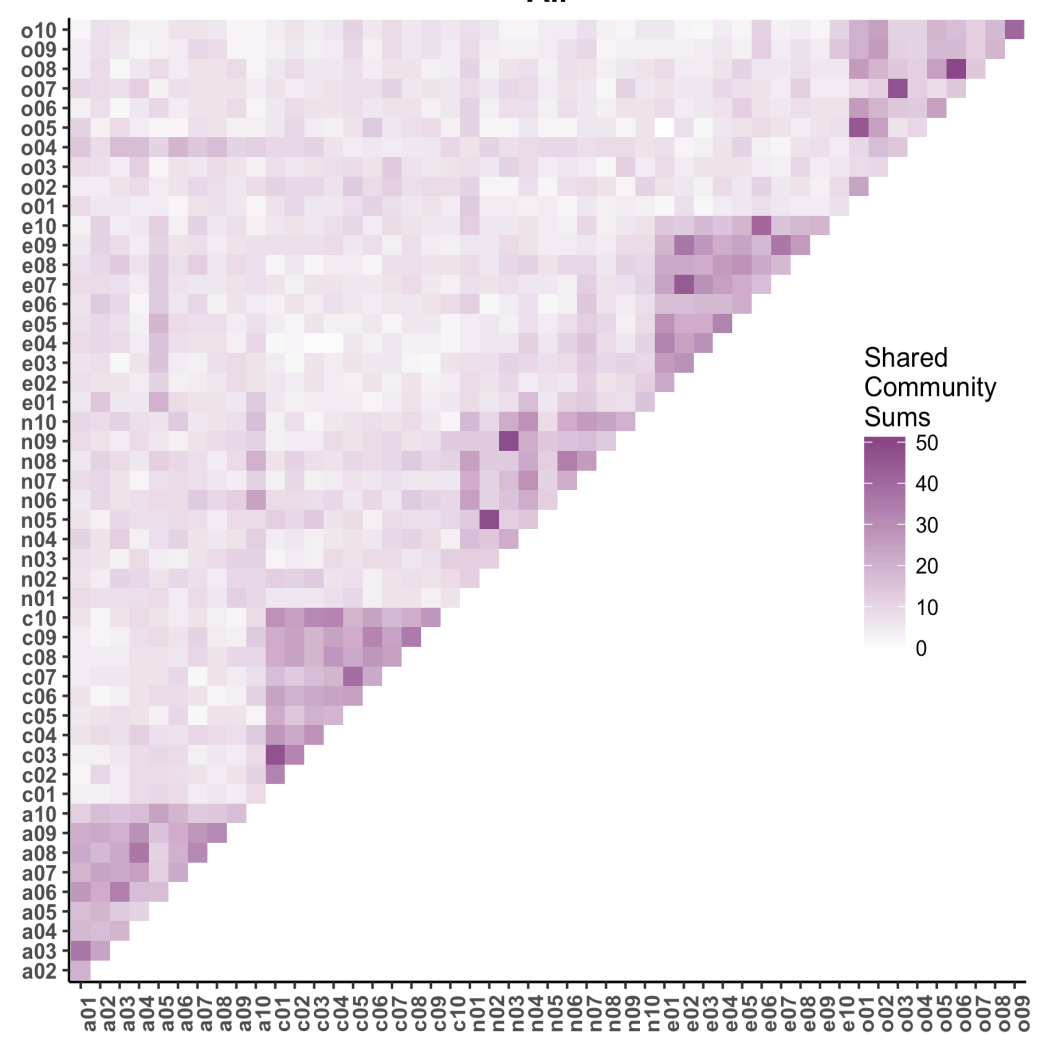

38 \& below

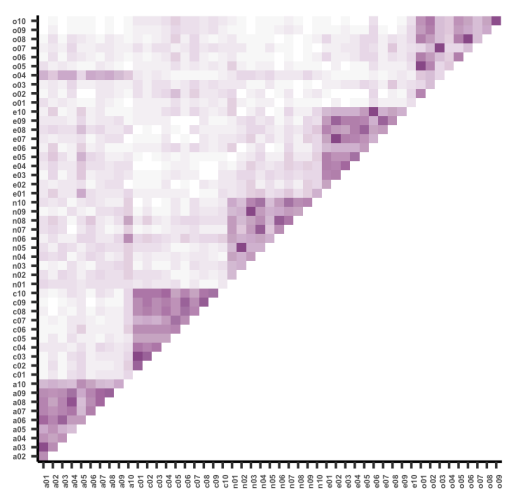

$39 \&$ above

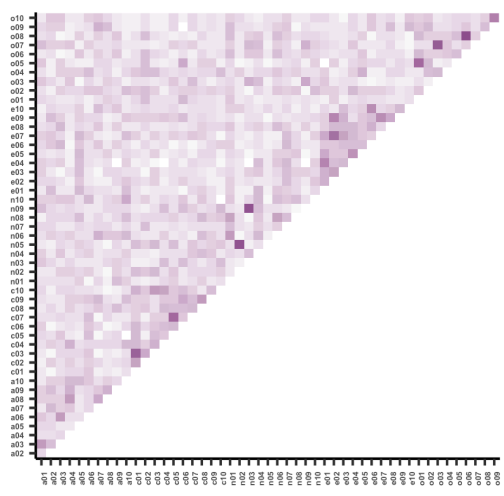

Figure 4. Frequency of shared community membership across items in (A) the full sample (B), participants 38 and below, (C) and participants 39 and above. Groups were split according to a median age split of all age groups for ease of comparing frequency, The diagonal of each plot indicates items within the same Big 5 scale, while off-diagonal elements are largely items of different scales. Darker colors indicate that the empirically derived community membership of two nodes was frequently shared across age groups, while lighter colors indicate that community membership was often not shared.

\section{Consistency}


Given lifespan changes in coherence and differentiation, we next assess the consistency of associations across the lifespan. To address this, we assess the profile stability of edge weights across the lifespan. We would expect network structure similarity to be a function of age differences, not age itself (e.g. the age difference between 15 and 20 is the same as between 55 and 60) if personality trait structure is consistent across adulthood. Figure 5 presents a heat map of profile associations across age groups. Consistency in network structure would be represented by a red band along the diagonal of the heat map that signals that adjacent ages are more similar to one another than non-adjacent ages. Departures from this pattern would suggest that structural differences are a function of age, and that the structure of the indicators of the Big Five are different at different points in the lifespan. As is clear in Figure 5a, differences in structure appear to be a function of both age and age differences. In the multi-trait network, there were surprisingly weak profile correlations above approximately age 30, even for adjacent ages. Instead, the strongest consistency appears reliably for the youngest participants in the sample. For older adults, there does not appear to be a strongly consistent structure of the Big Five. To better understand these patterns, we broke down the profiles into between and within-trait edges and calculated the profile correlations (see Figures $5 \mathrm{~b}$ and $5 \mathrm{c}$ ). Within-trait profiles were relatively stable across different age groups though relatively more correlated in ages 16 to 23 . Weak consistency appears to have been driven by cross-trait edges, which approach zero except for the youngest age groups. ${ }^{2}$ Given the greater number of connections (i.e., density) in the networks of older adults, this suggests that the lack of differentiation among Big Five in older adulthood may drive structural inconsistency.

\footnotetext{
${ }^{2}$ We also attained similar patterns of profile correlations for within-trait edges at the level of specific traits, both in the multi- and single-trait networks. The full results of these analyses are available in the online materials.
} 

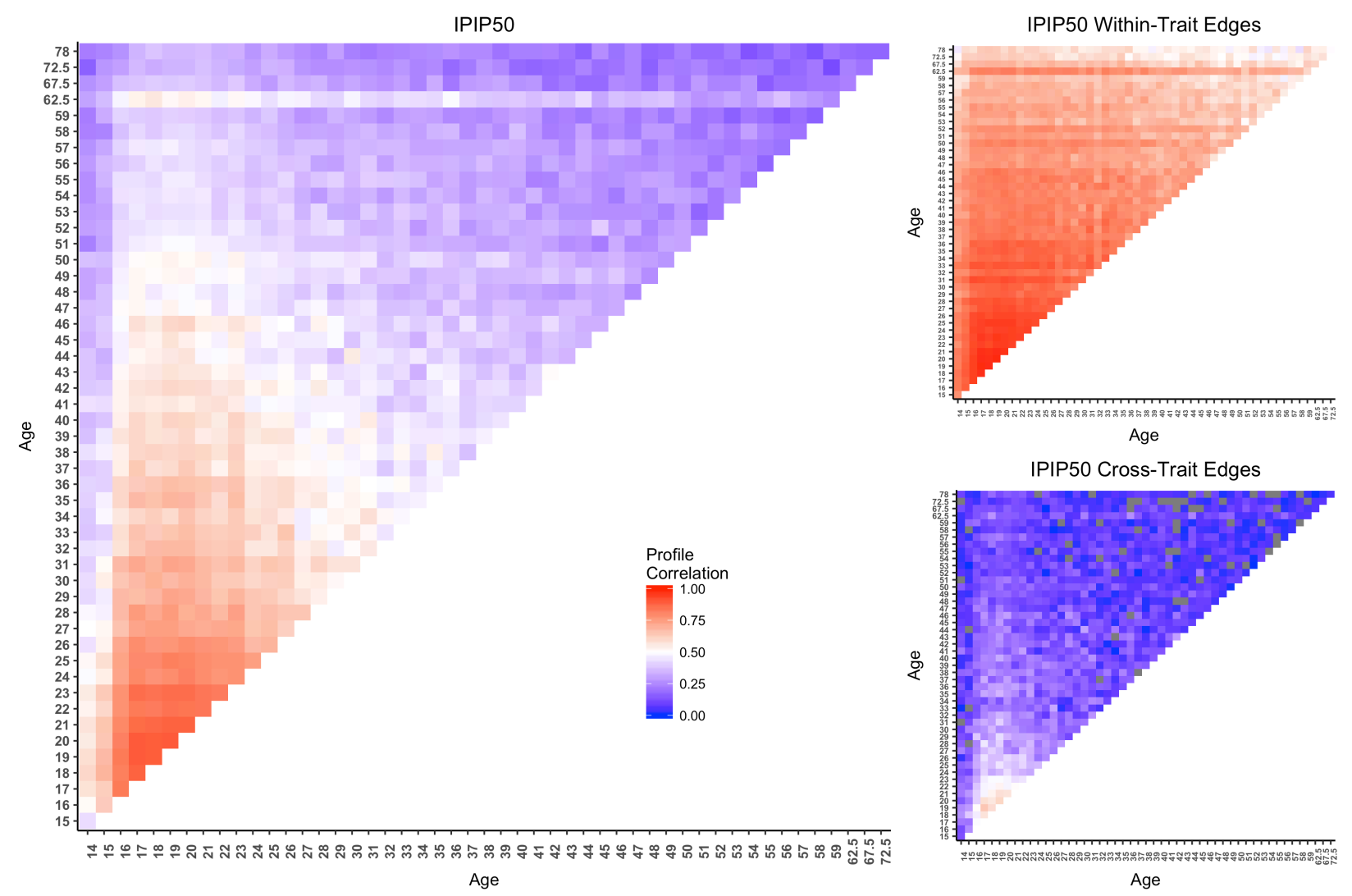

Figure 5. Consistency of network structure across age groups. $\mathrm{X}$ and $\mathrm{Y}$ axes represent age groups, while cells indicate the strength of the profile correlation between any two age groups. Consistency in network structure would be represented by a red band along the diagonal of the heat map that would signal that adjacent ages are more similar to one another than non-adjacent ages - that is, structural differences are a function of age differences, not age. Departures from this pattern would suggest that structural differences are a function of age, and that the structure of the indicators of the Big Five are different at different points in the lifespan.

\section{Discussion}

The current study tracked age differences in coherence, differentiation, and consistency of personality across the lifespan using a network approach. When modeled across the personality trait space of the Big Five, coherence within each trait remains quite stable across the lifespan, indicating that the traits manifest mostly the same in terms of similar behaviors being 
associated with the same behaviors across the lifespan (e.g., organization and responsibility components of conscientiousness covary at similar levels across the lifespan). Differentiation weakens across the lifespan, indicating that the items of each trait are more likely to be associated with or have "cross loadings" with other traits. Weaker differentiation may suggest either a more complex structure of personality or decreased relevance of item indicators across age (or both). Consistent with this, network consistency across ages was strong for young adults but considerably weaker for older adults. Moreover, consistency was stronger for within-trait associations than for between-trait, but on the whole, consistency remained stronger for young adults. Overall, these findings suggest that the structure of the Big Five may not be the optimal structure for ages outside of young adulthood.

\section{Age Differences in Coherence and Differentiation}

Personality networks of young adults were coherent, differentiated, and consistent, within both single and multi-trait networks. Patterns of coherence and differentiation, further, did not appear to be driven by a single or set of traits, instead applying to all of the Big Five. In line with past research, coherence, differentiation, and consistency improved in adolescence, peaking in young adulthood (Soto et al., 2011). Strong improvements in coherence and differentiation during this time explain why the factor structure of the Big Five begins to be extracted within this age range, compared to earlier ages where the Big Five structure is not as ideal (Soto et al., 2008; Soto \& Tackett, 2015). These findings are in line with the historical development of the Big Five, which tended to use mostly younger adults (Norman, 1963; Cattell et al., 1970; Digman \& Takemoto-Chock, 1981; Goldberg, 1990) and young Air Force officers (Tupes \& Christal, 1961) to establish the factor structure. Indeed, our unique examination of the adequacy 
of the Big Five structure suggests that the Big Five is an excellent parsimonious representation of the structure of personality differences during young adulthood.

In contrast, older adults' personality networks were coherent but not differentiated or consistent. Although coherence continued to improve across early adulthood lifespan, differentiation weakened. In other words, there were more and stronger cross-loadings among items of different traits. These cross-loadings explain why the Big Five structure was extracted from younger but not older adults using community structure analysis. Moreover, the crossloadings highlight that concern may be warranted when using the Big Five structure to understand personality among older adults. While meaningful interpretation at the level of individual traits remains (due to modest levels of coherence), low levels of differentiation suggest that alternative factor structures in older adulthood are needed. Future investigations should prioritize structures that account for weaker differentiation, by for example using more exploratory methods (ESEM; Marsh et al., 2013) or perhaps, using idiographic approaches (e.g., Beck \& Jackson, 2019a, b). Indeed, the results of the present study align with calls for more carefully accounting for or allowing cross-loadings of items when fitting factor analytic models (Goldberg \& Velicer, 2006; Hopwood \& Donnellan, 2010).

On the one hand, weakening differentiation and increases in the number and magnitude of connections in general may signal that the personalities of older adults are less complex than those of younger adults. That is, for older adults, the connections among personality manifestations are so many and strong that all components of personality tend to covary along similar poles of the Big Five (i.e. higher levels of Extraversion, Agreeableness, Conscientiousness, Openness and lower levels of Neuroticism). In support for this, there is some evidence of a general factor of personality (Davies et al., 2015), as well as a general factor of 
psychopathology (Caspi et al.. 2014 ). Importantly, investigations of these single factor models tend not to solely rely among younger adults (Erdle \& Rushton, 2011). On the other hand, weakening differentiation could signal that older adults' personalities are more complex, necessitating a more nuanced factor structure. As individuals age, they gain more experiences, more autonomy and more resources to shape their environment, resulting in more complex personalities. This could lead to more intricate associations of behaviors across traits and people, rendering parsimonious orthogonal factor structures untenable.

Changes in the structure of personality across the lifespan parallel observed changes in both cognition and emotion. With age, the structure of cognitive ability has been suggested to both become more and less coherent. Indeed, according to the differentiation hypothesis of cognitive ability, changes in its organization with age goes from a from a fairly cohesive set of abilities to a more loosely organized group (Garrett, 1946). However, follow-up longitudinal work suggests that cognitive ability is characterized by increasing differentiation in adolescence and early adulthood followed by worsening differentiation - or dedifferentiation - in older adulthood (Baltes, Cornelius, Spiro, Nesselroade, \& Willis, 1980; Lienert \& Crott, 1964; McHugh \& Owens, 1954). Cattell $(1971,1987)$ proposed that this occurs because abilities are invested in more domains across the lifespan that are often associated with age-graded experiences. Others followed up on Cattell's proposition suggesting that learning in childhood promotes the proliferation of new abilities, while aging processes in older adulthood limit the manifestation of these unique abilities, resulting in the appearance of a more unified structure (Baltes \& Lindenberger, 1997; Li et al., 2004; Lovden, Ghisletta, \& Lindenberger, 2004).

Similarly, there is the thought that resources are used to focus emotional experiences differently among older adults compared to younger adulthoods and that emotional experiences 
become more complex across the course of the lifespan (Carstensen, Fung, \& Charles, 2003;

Carstensen, Pasupathi, \& Nesselroade, 2000; Labouvie-Vief \& Medler, 2002) . Like cognitive ability, increased complexity (differentiation) of emotion across age groups may be a function of current age-graded experiences, past experiences, and the cultural context into which one is embedded (Barrett, 2004). However, more recent evidence suggests that emotion shows a similar pattern of differentiation followed by dedifferentiation (Hay \& Diehl, 2011).

Together, these findings suggest that lifespan development of psychological constructs like personality, cognition, and emotion must be examined through multiple metrics of change. Mean-level, rank-order, and individual differences in mean-level change are most commonly examined within an aging framework, but structural changes appear also be quite common. Further, these changes impact the interpretation of the predictive validity of personality traits. If different factor structures exist at different ages, then there will be under-estimation of true personality to outcome associations, due to the imprecise assessment of personality. Moreover, the tendency to find the incremental validity of multiple personality assessments at different ages (Hill, Edmonds \& Jackson, 2019) may not be due to different mechanism that exist across the lifespan (e.g. personality $\rightarrow$ health associations that differ in young vs older adulthood) but due to examining different constructs.

\section{Alternative Personality Factor Structures}

Weakening differentiation in the network structure of older adults' personalities relative to younger adults parallels concerns over lack of simple structure when fitting confirmatory factor models of personality in older adulthood (Hopwood \& Donnellan, 2010). The lack of differentiation highlights the lack of independence of indicators across traits, which violates simple structure. The violation of simple structure raises a question of the appropriateness of 
using Big Five scales to measure personality processes across the lifespan and to use personality traits to predict subsequent outcomes, such as mortality, health, and education.

Unfortunately, the lack of fit of the Big Five in older adulthood does not clarify the best path forward. Multiple suggestions for dealing with the lack of simple structure have been put forth. One option is that new factor models should be put forth that are constructed using more representative age samples and which allow for assessment of the trait space using independent hierarchical and heterarchical organizational frameworks (Condon, 2018). It may be the case that broader factors above the Big Five or below through lower-order facet domains show similar structure across the lifespan. Or, at the very least, if there are no similar components across the lifespan, then a hierarchically defined personality trait space is a means to understand where and when the differences arise. Consistent with the utility of a hierarchical treatment of personality trait space, different developmental trends are found for facets (Chopik, 2016; Jackson et al., 2009; Soto. et al., 2011), and items (Mõttus et al., 2015; Mõttus et al., 2018).

Other alternative paths forward may follow from the substantial heterogeneity in the structure of personality at the level of the individual. Instead of a search for a nomothetic structure that is similar across people, perhaps the personality trait space is better investigated within a person - that is, idiographically (Molenaar, 2004). The idiographic assessment of personality has been long discussed as the optimal level of personality assessment (Allport, 1937, Cattell, 1947, 1957) but progress in idiographic assessment has been held back primarily due to quantitative concerns (Beck \& Jackson, 2019c; Piccirillo, Beck, \& Rodebaugh, 2019). Time series data that include many assessments within a person are necessary to answer such questions. Traditional collection and analysis methods made this type of data difficult to obtain and analyze, but the prevalence of smart phones and novel methods make idiographic treatments 
of personality more accessible. The small number of studies that have attempted to examine personality traits idiographically find that individuals largely do not mirror a Big Five structure and show substantial interindividual differences in intraindividual structure (Beck \& Jackson, 2019a; Borkenau \& Ostendorpf, 1998; Molenaar, 2004). However, no investigations have investigated lifespan differences in idiographic personality structure.

From a network perspective, the observed commonalities that result in somewhat similar personality structures at different points in the lifespan are seen as emergent properties of complex patterns among the indicators - that is, emergence. As noted previously, dedifferentiation processes may reflect increasing complexity in manifestations of personality. Increasing complexity, which results in more and stronger connections among indicators, may make the structure of personality more vulnerable to perturbations (Cramer et al., 2016; van de Leemput et al., 2014). When there are more and stronger connections, small, common perturbations like aging processes may influence a small number of manifestations, but the strong interrelations lead to cascading effects that result in strong influences across the level of the system as a whole. Thus, the increased inconsistency of personality networks in the older age ranges may signal that the network is vulnerable such that relatively small behavioral changes could move the system toward more lasting, dramatic change.

\section{Limitations and Future Directions}

The present findings are limited in many regards that point to future areas of investigation. First, the "developmental" patterns we noted are cross-sectional, not longitudinal. Only with a longitudinal design can we begin to assess the person and environmental factors that elicit consistency and change in personality networks. Moreover, long-term longitudinal studies would allow for the estimation of idiographic personality structures for each participant which 
directly reflect the personality of that person rather than broad patterns of between person individual differences.

Second, we constrained our analyses to a personality trait space suggested by the Big Five, making it unclear how the addition or removal of other trait content to the network may impact the structure or relationship between indicators. Weak consistency in the older age ranges of the sample may highlight that there are components of the personality system that are not captured within the Big Five or that current indicators are no longer valid. Future research should more closely examine age-related differences in personality structure using larger item pools.

Third, we modeled personality network differences as a function of age, which ignores within-group heterogeneity due to life events or demographic factors. Cross-sectional studies of mean-level personality differences suggest that men and women exhibit different age trends in some facets and traits (Soto et al., 2011), highlighting the necessity of such analyses. Moreover, particularly in older adulthood, where the observed personality networks are denser but less stable, individuals' personalities may be changing. According to Social Investment Theory, the root of such change likely lies in age-graded social roles of changes individuals experience (Lodi-Smith \& Roberts, 2007). Future research should examine the relationship between crosssectional network stability and known social changes in older adulthood, including losses of loved ones (Mroczek \& Spiro, 2003), retirement (Mike, Jackson, \& Oltmanns, 2014), dementia (Balsis et al., 2005), and other health-related concerns (Jackson, Weston \& Schultz, 2017).

\section{Conclusions}

Coherence and differentiation have been primarily investigated in adolescence, a time in the lifespan that Big Five structure may not be ideal. The current study extended this investigation across the lifespan and found that personality trait associations are coherent, differentiated, and 
consistent for the younger adulthood, likely reflecting the properties of the samples used in early research on the Big Five. In contrast, while older adults were similarly coherent, they evidenced low differentiation and less consistency. Age trends in coherence and differentiation highlight the importance to using models that do not assume perfect differentiation between traits and suggest that older adults have a different structure of personality than younger adults. 


\section{References}

Allemand, M., Zimprich, D., \& Hendriks, A. A. (2008). Age differences in five personality domains across the life span. Developmental Psychology, 44(3), 758.

Allemand, M., Zimprich, D., \& Hertzog, C. (2007). Cross-sectional age differences and longitudinal age changes of personality in middle adulthood and old age. Journal of Personality, 75(2), 323-358.

Allport, G. W. (1937). Personality: A psychological interpretation.

Allport, G. W., \& Odbert, H. S. (1936). Trait-names: A psycho-lexical study. Psychological Monographs, 47(1), i.

Balsis, S., Carpenter, B. D., \& Storandt, M. (2005). Personality change precedes clinical diagnosis of dementia of the Alzheimer type. The Journals of Gerontology Series B: Psychological Sciences and Social Sciences, 60(2), P98-P101.

Baltes, P. B. (1997). On the incomplete architecture of human ontogeny: Selection, optimization, and compensation as foundation of developmental theory. American Psychologist, 52(4), 366.

Baltes, P. B., Cornelius, S. W., Spiro, A., Nesselroade, J. R., \& Willis, S. L. (1980). Integration versus differentiation of fluid/crytallized intelligence in old age. Developmental Psychology, 16(6), 625.

Baltes, P. B., \& Lindenberger, U. (1997). Emergence of a powerful connection between sensory and cognitive functions across the adult life span: a new window to the study of cognitive aging?. Psychology and aging, 12(1), 12.

Barrett, L. F. (2004). Feelings or words? Understanding the content in self-report ratings of experienced emotion. Journal of Personality and Social Psychology, 87(2), 266. 
Barrick, M. R., \& Mount, M. K. (1991). The big five personality dimensions and job performance: a meta-analysis. Personnel psychology, 44(1), 1-26.

Barrick, M. R., Mount, M. K., \& Judge, T. A. (2001). Personality and performance at the beginning of the new millennium: What do we know and where do we go next?. International Journal of Selection and Assessment, 9(1-2), 9-30.

Beck, E. D., \& Jackson, J. J. (2019a). Consistency and change in idiographic personality: A longitudinal ESM network study. Journal of Personality and Social Psychology.

Beck, E. D. and Jackson, J. J. (2019b). Network approaches to representing and understanding psychological dynamics. In Wood, D., Read, S., Harms, P., and Slaughter, A., editors, Measuring and Modeling the Person and Situation. Elsevier, 1st edition.

Beck, E. D. and Jackson, J. J. (2019c). Within-person variability. In Rauthmann, J., editor, Handbook of Personality Dynamics and Processes. Elsevier, 1st edition.

Belsky, J., Jaffee, S. R., Caspi, A., Moffitt, T., \& Silva, P. A. (2003). Intergenerational relationships in young adulthood and their life course, mental health, and personality correlates. Journal of Family Psychology, 17(4), 460.

Benet-Martinez, V., \& John, O. P. (1998). Los Cinco Grandes across cultures and ethnic groups: Multitrait-multimethod analyses of the Big Five in Spanish and English. Journal of Personality and Social Psychology, 75(3), 729.

Block, J. (2010). The five-factor framing of personality and beyond: Some ruminations. Psychological Inquiry, 21(1), 2-25.

Blondel, V. D., Guillaume, J. L., Lambiotte, R., \& Lefebvre, E. (2008). Fast unfolding of communities in large networks. Journal of statistical mechanics: theory and experiment, 2008(10), P10008. 
Borkenau, P., \& Ostendorf, F. (1998). The Big Five as states: How useful is the five-factor model to describe intraindividual variations over time?. Journal of Research in Personality, 32(2), 202-221.

Borsboom, D., Mellenbergh, G. J., \& Van Heerden, J. (2003). The theoretical status of latent variables. Psychological Review, 110(2), 203.

Busato, V. V., Prins, F. J., Elshout, J. J., \& Hamaker, C. (2000). Intellectual ability, learning style, personality, achievement motivation and academic success of psychology students in higher education. Personality and Individual Differences, 29(6), 1057-1068.

Carstensen, L. L., Fung, H. H., \& Charles, S. T. (2003). Socioemotional selectivity theory and the regulation of emotion in the second half of life. Motivation and Emotion, 27(2), 103123.

Carstensen, L. L., Pasupathi, M., Mayr, U., \& Nesselroade, J. R. (2000). Emotional experience in everyday life across the adult life span. Journal of Personality and Social Psychology, 79(4), 644.

Caspi, A., Houts, R. M., Belsky, D. W., Goldman-Mellor, S. J., Harrington, H., Israel, S., ... \& Moffitt, T. E. (2014). The p factor: one general psychopathology factor in the structure of psychiatric disorders?. Clinical Psychological Science, 2(2), 119-137.

Cattell, R. B. (1947). Confirmation and clarification of primary personality factors. Psychometrika, 12(3), 197-220.

Cattell, R. B. (1957). Personality and motivation structure and measurement.

Cattell, R. B. (1971). Abilities: Their structure, growth, and action.

Cattell, R. B. (1987). Intelligence: Its structure, growth and action (Vol. 35). Elsevier. 
Cattell, R. B., Eber, H. W., \& Tatsuoka, M. M. (1970). Handbook for the sixteen personality factor questionnaire (16 PF): In clinical, educational, industrial, and research psychology, for use with all forms of the test. Institute for Personality and Ability Testing.

Chen, J., \& Chen, Z. (2008). Extended Bayesian information criteria for model selection with large model spaces. Biometrika, 95(3), 759-771.

Chopik, W. J. (2016). Age differences in conscientiousness facets in the second half of life: Divergent associations with changes in physical health. Personality and Individual Differences, 96, 202-211.

Condon, D. M. (2018). The SAPA Personality Inventory: An empirically-derived, hierarchicallyorganized self-report personality assessment model. PsyArXiv. https://doi.org/10.17605/osf.io/SC4P9

Costantini, G., \& Perugini, M. (2016). The network of conscientiousness. Journal of Research in Personality, 65, 68-88.

Cramer, A. O., van Borkulo, C. D., Giltay, E. J., van der Maas, H. L., Kendler, K. S., Scheffer, M., \& Borsboom, D. (2016). Major depression as a complex dynamic system. PloS one, 11(12), e0167490.

Cramer, A. O., Van der Sluis, S., Noordhof, A., Wichers, M., Geschwind, N., Aggen, S. H., ... \& Borsboom, D. (2012). Dimensions of normal personality as networks in search of equilibrium: You can't like parties if you don't like people. European Journal of Personality, 26(4), 414-431.

Csardi, G., \& Nepusz, T. (2006). The igraph software package for complex network research. InterJournal, Complex Systems, 1695(5), 1-9. 
Davies, S. E., Connelly, B. S., Ones, D. S., \& Birkland, A. S. (2015). The General Factor of Personality: The "Big One," a self-evaluative trait, or a methodological gnat that won't go away?. Personality and Individual Differences, 81, 13-22.

Denissen, J. J., Geenen, R., Van Aken, M. A., Gosling, S. D., \& Potter, J. (2008). Development and validation of a Dutch translation of the Big Five Inventory (BFI). Journal of personality Assessment, 90(2), 152-157.

De Raad, B., \& Schouwenburg, H. C. (1996). Personality in learning and education: A review. European Journal of personality, 10(5), 303-336.

Digman, J. M., \& Takemoto-Chock, N. K. (1981). Factors in the natural language of personality: Re-analysis, comparison, and interpretation of six major studies. Multivariate behavioral research, 16(2), 149-170.

Donnellan, M. B., Larsen-Rife, D., \& Conger, R. D. (2005). Personality, family history, and competence in early adult romantic relationships. Journal of Personality and Social Psychology, 88(3), 562.

Donnellan, M. B., \& Lucas, R. E. (2008). Age differences in the big five across the life span: evidence from two national samples. Psychology and Aging, 23(3), 558.

Donnellan, M. B., Oswald, F. L., Baird, B. M., \& Lucas, R. E. (2006). The Mini-IPIP Scales: Tiny-yet-effective measures of the Big Five Factors of Personality. Psychological Assessment, 18(2), 192-203. http://dx.doi.org/10.1037/1040-3590.18.2.192

Duckworth, A. L., Weir, D. R., Tsukayama, E., \& Kwok, D. (2012). Who does well in life? Conscientious adults excel in both objective and subjective success. Frontiers in Psychology, 3, 356. 
Epskamp, S. (2016b). Regularized Gaussian psychological networks: Brief report on the performance of extended BIC model selection. arXiv preprint arXiv: 1606.05771.

Epskamp, S., Cramer, A. O., Waldorp, L. J., Schmittmann, V. D., \& Borsboom, D. (2012). qgraph: Network visualizations of relationships in psychometric data. Journal of Statistical Software, 48(4), 1-18.

Epskamp, S., \& Fried, E. I. (2018). A tutorial on regularized partial correlation networks. Psychological Methods.

Erdle, S., \& Rushton, J. P. (2011). Does self-esteem or social desirability account for a general factor of personality (GFP) in the Big Five?. Personality and Individual Differences, 50(7), 1152-1154.

Freund, A. M., Li, K. Z. H., \& Baltes, P. B. (1999). The role of selection, optimization, and compensation in successful aging. Action and development: Origins and functions of intentional self-development, 401-434.

Friedman, J., Hastie, T., \& Tibshirani, R. (2008). Sparse inverse covariance estimation with the graphical lasso. Biostatistics, 9(3), 432-441.

Fruchterman, T. M., \& Reingold, E. M. (1991). Graph drawing by force-directed placement. Software: Practice and experience, 21(11), 1129-1164.

Galton, F. (1884). Measurement of character. Fortnightly, 36(212), 179-185.

Garrett, H. E. (1946). A developmental theory of intelligence. American Psychologist, 1(9), 372.

Goldberg, L. R. (1990). An alternative" description of personality": the big-five factor structure. Journal of Personality and Social Psychology, 59(6), 1216.

Goldberg, L. R. (1992). The development of markers for the Big-Five factor structure. Psychological Assessment, 4(1), 26. 
Goldberg, L. R. (1999). A broad-bandwidth, public domain, personality inventory measuring the lower-level facets of several five-factor models. Personality Psychology in Europe, 7(1), $7-28$.

Goldberg, L. R., Johnson, J. A., Eber, H. W., Hogan, R., Ashton, M. C., Cloninger, C. R., \& Gough, H. G. (2006). The international personality item pool and the future of publicdomain personality measures. Journal of Research in Personality, 40(1), 84-96.

Goldberg, L. R., \& Velicer, W. F. (2006). Principles of exploratory factor analysis. Differentiating Normal and Abnormal Personality, 2, 209-337.

Harris, K., \& Vazire, S. (2016). On friendship development and the Big Five personality traits. Social and Personality Psychology Compass, 10(11), 647-667.

Hay, E. L., \& Diehl, M. (2011). Emotion complexity and emotion regulation across adulthood. European Journal of Ageing, 8(3), 157-168.

Hill, P. L., Edmonds, G. W., \& Jackson, J. J. (2019). Pathways Linking Childhood Personality to Later Life Outcomes. Child Development Perspectives, 13(2), 116-120.

Hopwood, C. J., \& Donnellan, M. B. (2010). How should the internal structure of personality inventories be evaluated?. Personality and Social Psychology Review, 14(3), 332-346.

Jackson, J. J., \& Allemand, M. (2014). Moving personality development research forward: Applications using structural equation models. European Journal of Personality, 28(3), 300-310.

Jackson, J. J., Bogg, T., Walton, K. E., Wood, D., Harms, P. D., Lodi-Smith, J., ... \& Roberts, B. W. (2009). Not all conscientiousness scales change alike: A multimethod, multisample study of age differences in the facets of conscientiousness. Journal of Personality and Social Psychology, 96(2), 446. 
Jackson, J. J., Connolly, J. J., Garrison, S. M., Leveille, M. M., \& Connolly, S. L. (2015). Your friends know how long you will live: A 75-year study of peer-rated personality traits. Psychological Science, 26(3), 335-340.

Jackson, J. J., Weston, S. J., \& Schultz, L. H. (2017). Personality development and health. In Personality development across the lifespan (pp. 371-384). Academic Press.

Labouvie-Vief, G., \& Medler, M. (2002). Affect optimization and affect complexity: Modes and styles of regulation in adulthood. Psychology and Aging, 17(4), 571.

Li, S. C., Lindenberger, U., Hommel, B., Aschersleben, G., Prinz, W., \& Baltes, P. B. (2004). Transformations in the couplings among intellectual abilities and constituent cognitive processes across the life span. Psychological science, 15(3), 155-163.

Lienert, G. A., \& Crott, H. W. (1964). Studies on the factor structure of intelligence in children, adolescents, and adults. Vita Humana.

Lodi-Smith, J., \& Roberts, B. W. (2007). Social investment and personality: A meta-analysis of the relationship of personality traits to investment in work, family, religion, and volunteerism. Personality and Social Psychology Review, 11(1), 68-86.

Lord, F. M. (1955). Estimation of parameters from incomplete data. Journal of the American Statistical Association, 50(271), 870-876.

Lorenzo-Seva, U., \& Ten Berge, J. M. (2006). Tucker's congruence coefficient as a meaningful index of factor similarity. Methodology, 2(2), 57-64.

Lövdén, M., Ghisletta, P., \& Lindenberger, U. (2004). Cognition in the Berlin Aging Study (BASE): the first 10 years. Aging Neuropsychology and Cognition, 11(2-3), 104-133.

Lucas, R. E., \& Donnellan, M. B. (2009). Age differences in personality: Evidence from a nationally representative Australian sample. Developmental Psychology, 45(5), 1353. 
Marsh, H. W., Lüdtke, O., Nagengast, B., Trautwein, U., Morin, A. J., Abduljabbar, A. S., \& Köller, O. (2012). Classroom climate and contextual effects: Conceptual and methodological issues in the evaluation of group-level effects. Educational Psychologist, 47(2), 106-124.

Marsh, H. W., Nagengast, B., \& Morin, A. J. (2013). Measurement invariance of big-five factors over the life span: ESEM tests of gender, age, plasticity, maturity, and la dolce vita effects. Developmental Psychology, 49(6), 1194.

McCrae, R. R., Costa, P. T., de Lima, M. P., Simões, A., Ostendorf, F., Angleitner, A., ... \& Chae, J. H. (1999). Age differences in personality across the adult life span: parallels in five cultures. Developmental Psychology, 35(2), 466.

McCrae, R. R., \& Terracciano, A. (2005). Universal features of personality traits from the observer's perspective: data from 50 cultures. Journal of Personality and Social Psychology, 88(3), 547.

McCrae, R. R., Zonderman, A. B., Costa Jr, P. T., Bond, M. H., \& Paunonen, S. V. (1996). Evaluating replicability of factors in the Revised NEO Personality Inventory: Confirmatory factor analysis versus Procrustes rotation. Journal of Personality and Social Psychology, 70(3), 552.

McHugh, R. B., \& Owens, W. A. (1954). Age changes in mental organization-a longitudinal study. Journal of Gerontology.

McNeish, D. (2018). Thanks coefficient alpha, we'll take it from here. Psychological Methods, $23,412-433$. 
Mike, A., Jackson, J. J., \& Oltmanns, T. F. (2014). The conscientious retiree: The relationship between conscientiousness, retirement, and volunteering. Journal of Research in Personality, 52, 68-77.

Molenaar, P. C. (2004). A manifesto on psychology as idiographic science: Bringing the person back into scientific psychology, this time forever. Measurement, 2(4), 201-218.

Mõttus, R., Bates, T. C., Condon, D. M., Mroczek, D. K., Revelle, W. R. (2018). Your personality data can do more: Items provide leverage for explaining the variance and covariance of life outcomes. PsyArXiv. https://doi.org/10.17605/osf.io/4Q9GV

Mõttus, R., Johnson, W., \& Deary, I. J. (2012). Personality traits in old age: Measurement and rank-order stability and some mean-level change. Psychology and Aging, 27(1), 243.

Mõttus, R., Realo, A., Allik, J., Esko, T., Metspalu, A., \& Johnson, W. (2015). Within-trait heterogeneity in age group differences in personality domains and facets: Implications for the development and coherence of personality traits. PloS one, 10(3), e0119667.

Mroczek, D. K., \& Spiro III, A. (2003). Modeling intraindividual change in personality traits: Findings from the Normative Aging Study. The Journals of Gerontology Series B: Psychological Sciences and Social Sciences, 58(3), 153-165.

Norman, W. T. (1963). Toward an adequate taxonomy of personality attributes: Replicated factor structure in peer nomination personality ratings. The Journal of Abnormal and Social Psychology, 66(6), 574.

Nye, C. D., Allemand, M., Gosling, S. D., Potter, J., \& Roberts, B. W. (2016). Personality trait differences between young and middle-aged adults: Measurement artifacts or actual trends?. Journal of Personality, 84(4), 473-492. 
Olaru, G., Schroeders, U., Wilhelm, O., \& Ostendorf, F. (2018). A confirmatory examination of age-associated personality differences: Deriving age-related measurement-invariant solutions using ant colony optimization. Journal of personality, 86(6), 1037-1049.

Pettersson, E., \& Turkheimer, E. (2010). Item selection, evaluation, and simple structure in personality data. Journal of Research in Personality, 44(4), 407-420.

Piccirillo, M. L., Beck, E. D., \& Rodebaugh, T. L. (2019). A clinician's primer for idiographic research: Considerations and recommendations. Behavior Therapy.

Reichardt, J., \& Bornholdt, S. (2006). Statistical mechanics of community detection. Physical Review E, 74(1), 016110.

Revelle, W. R. \& Condon, D. M. (in press). Reliability from $\alpha$ to $\omega$. Psychological Assessment.

Revelle, W., Condon, D. M., Wilt, J., French, J. A., Brown, A., \& Elleman, L. G. (2016). Web and phone based data collection using planned missing designs. Sage handbook of online research methods (2nd ed., p. 578-595). Sage Publications, Inc.

Roberts, B. W., \& Mroczek, D. (2008). Personality trait change in adulthood. Current Directions in Psychological Science, 17(1), 31-35.

Robins, R. W., Caspi, A., \& Moffitt, T. E. (2002). It's not just who you're with, it's who you are: Personality and relationship experiences across multiple relationships. Journal of Personality, 70(6), 925-964.

Saucier, G., \& Ostendorf, F. (1999). Hierarchical subcomponents of the big five personality factors: A cross-language replication. Journal of Personality and Social Psychology, 76(4), 613. 
Schmittmann, V. D., Cramer, A. O., Waldorp, L. J., Epskamp, S., Kievit, R. A., \& Borsboom, D. (2013). Deconstructing the construct: A network perspective on psychological phenomena. New Ideas in Psychology, 31(1), 43-53.

Small, B. J., Hertzog, C., Hultsch, D. F., \& Dixon, R. A. (2003). Stability and change in adult personality over 6 years: Findings from the Victoria Longitudinal Study. The Journals of Gerontology Series B: Psychological Sciences and Social Sciences, 58(3), P166-P176.

Solomon, B. C., \& Jackson, J. J. (2014). Why do personality traits predict divorce? Multiple pathways through satisfaction. Journal of Personality and Social Psychology, 106(6), 978.

Soto, C. J., John, O. P., Gosling, S. D., \& Potter, J. (2008). The developmental psychometrics of big five self-reports: Acquiescence, factor structure, coherence, and differentiation from ages 10 to 20. Journal of Personality and Social Psychology, 94(4), 718.

Soto, C. J., John, O. P., Gosling, S. D., \& Potter, J. (2011). Age differences in personality traits from 10 to 65: Big Five domains and facets in a large cross-sectional sample. Journal of Personality and Social Psychology, 100(2), 330.

Soto, C. J., \& Tackett, J. L. (2015). Personality traits in childhood and adolescence: Structure, development, and outcomes. Current Directions in Psychological Science, 24(5), 358362.

Specht, J., Egloff, B., \& Schmukle, S. C. (2011). Stability and change of personality across the life course: The impact of age and major life events on mean-level and rank-order stability of the Big Five. Journal of Personality and Social Psychology, 101(4), 862.

Tackett, J. L., Balsis, S., Oltmanns, T. F., \& Krueger, R. F. (2009). A unifying perspective on personality pathology across the life span: Developmental considerations for the fifth 
edition of the Diagnostic and Statistical Manual of Mental Disorders. Development and psychopathology, 21(3), 687-713.

Tibshirani, R. (1996). Regression shrinkage and selection via the lasso. Journal of the Royal Statistical Society: Series B (Methodological), 58(1), 267-288.

Tucker-Drob, E. M., \& Briley, D. A. (2014). Continuity of genetic and environmental influences on cognition across the life span: A meta-analysis of longitudinal twin and adoption studies. Psychological bulletin, 140(4), 949.

Tupes, E. C., \& Christal, R. E. (1961). Recurrent personality factors based on trait ratings (ASDTR-61-97). Lackland Air Force Base, TX: Aeronautical Systems Division, Personnel Laboratory.

Turiano, N. A., Chapman, B. P., Gruenewald, T. L., \& Mroczek, D. K. (2015). Personality and the leading behavioral contributors of mortality. Health Psychology, 34(1), 51.

van de Leemput, I. A., Wichers, M., Cramer, A. O., Borsboom, D., Tuerlinckx, F., Kuppens, P., ... \& Derom, C. (2014). Critical slowing down as early warning for the onset and termination of depression. Proceedings of the National Academy of Sciences, 111(1), 8792.

Weston, S. J., Gladstone, J. J., Graham, E. K., Mroczek, D. K., \& Condon, D. M. (2018). Who Are the Scrooges? Personality Predictors of Holiday Spending. Social Psychological and Personality Science, 1948550618792883.

Weston, S. J., Hill, P. L., \& Jackson, J. J. (2015). Personality traits predict the onset of disease. Social Psychological and Personality Science, 6(3), 309-317. 
Wilson, R. E., Harris, K., \& Vazire, S. (2015). Personality and friendship satisfaction in daily life: Do everyday social interactions account for individual differences in friendship satisfaction?. European Journal of Personality, 29(2), 173-186. DOI: 10.1002/per.1996 